\title{
Effect of Dip Time on Electrodeposited Zinc Oxide Nanofilm
}

\author{
Nonso Livinus Okoli ${ }^{1, ~}$, Chinwe Juliana Nkamuo ${ }^{2}$, Chukwuemeka Innocent Elekalachi ${ }^{3}$ \\ ${ }^{1}$ Department of Physics, Legacy University Okija, Okija, Nigeria \\ ${ }^{2}$ Department of Science Laboratory Technology, Federal Polytechnic Oko, Oko, Nigeria \\ ${ }^{3}$ Department of Industrial Physics, Chukwuemeka Odumegwu Ojukwu University, Uli, Nigeria \\ Email address: \\ okolinonsolivinus@gmail.com (N. L. Okoli), chybenas1@gmail.com (C. J. Nkamuo), emekainn@yahoo.com (C. I. Elekalachi) \\ ${ }^{*}$ Corresponding author
}

\section{To cite this article:}

Nonso Livinus Okoli, Chinwe Juliana Nkamuo, Chukwuemeka Innocent Elekalachi. Effect of Dip Time on Electrodeposited Zinc Oxide Nanofilm. American Journal of Materials Synthesis and Processing. Vol. 3, No. 2, 2018, pp. 7-11. doi: 10.11648/j.ajmsp.20180302.11

Received: June 16, 2018; Accepted: July 1, 2018; Published: July 23, 2018

\begin{abstract}
Nanofilms of Zinc Oxide ( $\mathrm{ZnO})$ were fabricated from solutions of zinc tetraoxosulphate heptahydrate, citric acid, and sodium hydroxide onto a Fluorine Tin Oxide (FTO) conductive glass by elecrodeposition process. Time as bath parameter was varied. Three samples with time interval of 30 seconds, 60 seconds and 90 seconds were fabricated. Absorbance of the films was determined with the help of spectrophotometer. Other optical properties of the nanofilms were calculated using the appropriate equations from the literature. The deposited nanofilms have high absorbance in UV region and low absorbance in VIS - NIR region. Transmittance of the nanofilms is low in UV region and high in VIS - NIR region. Reflectance of the films is low throughout the UV - VIS - NIR regions. The optimal optical thickness of $270 \mathrm{~nm}$ was obtained at 90 seconds. The bandgap of the nanofilms obtained is between 3.30 to $3.60 \mathrm{eV}$. Average crystallite size of $43.04 \mathrm{~nm}$ was obtained for the deposited $\mathrm{ZnO}$ thin film.
\end{abstract}

Keywords: Zinc Oxide, Electrodeposition, Nanofilms, Band Gap, Optical Properties, XRD

\section{Introduction}

Zinc oxide is an inorganic compound with the formula $\mathrm{ZnO} . \mathrm{ZnO}$ is a wide-bandgap semiconductor of the II-VI semiconductor group. $\mathrm{ZnO}$ materials show an n-type electrical conductivity due to its native or intrinsic defects such as oxygen vacancies and interstitial zinc atoms [1]. Intrinsic zinc oxide thin films are highly resistive in nature, but when commonly doped with Group III elements such as $\mathrm{Ga}$, in or $\mathrm{Al}$, they become conducting [2]. $\mathrm{ZnO}$ has received great interest owing to its favorable properties such as wide band gap (3.3 eV), optical transparency, electrical and piezoelectrical properties, high electron mobility, and strong room-temperature luminescence [3]. $\mathrm{ZnO}$ is a cheap, abundant, chemically stable and nontoxic material that has been widely used in optoelectronic devices, photovoltaic devices and surface acoustic wave devices and sensors. Those properties are valuable in emerging applications for: transparent electrodes in liquid crystal displays, energysaving or heat-protecting windows, and electronics as thinfilm transistors and light-emitting diodes.
Zinc oxide crystallizes in three forms: hexagonal wurtzite, cubic zincblende and the rarely observed cubic rocksalt [1]. The wurtzite structure is most stable at ambient conditions and thus most common. The zincblende form can be stabilized by growing $\mathrm{ZnO}$ on substrates with cubic lattice structure. In both cases, the zinc and oxide centers are tetrahedral, the most characteristic geometry for $\mathrm{Zn}$ (II). $\mathrm{ZnO}$ converts to the rocksalt motif at relatively high pressures about $10 \mathrm{GPa}$ [4].

$\mathrm{ZnO}$ has a relatively large direct band gap of $\sim 3.3 \mathrm{eV}$ at room temperature. Advantages associated with a large band gap include higher breakdown voltages, ability to sustain large electric fields, lower electronic noise, and hightemperature and high-power operation. The bandgap of $\mathrm{ZnO}$ can further be tuned to $\sim 3-4 \mathrm{eV}$ by its alloying with magnesium oxide or cadmium oxide [4].

Many techniques have been used for depositing high quality $\mathrm{ZnO}$ thin films. Some of them are electrodeposition technique [5, 6], electrospinning technique [7], pulsed laser deposition [8], RF sputtering [9], chemical solution deposition $[10,11]$, electron beam evaporation $[12,13]$, the 
sol - gel method [14], spray pyrolysis [15, 16], ultrasonic spray pyrolysis technique [3].

Cathodic electrodeposition technique has been recognized as the effective method for the production of metal oxide thin films, particularly $\mathrm{ZnO}$ thin films due to its simplicity, low temperature process, high deposition rate, low cost technique and suitability for large area substrate. This technique used a very low cathode voltage or current to produce the $\mathrm{ZnO}$ thin film on any conductive substrate such as a transparent conducting oxide [5] or any other metal plate [17]. In this deposition technique, the film thickness, electrical structural, morphology and optical properties can be controlled by the various deposition parameters such as: current density, applied potential, deposition time and the concentration of the electrolytic bath. In this work, $\mathrm{ZnO}$ thin films were electrodeposited at room temperature at varying deposition time.

\section{Materials and Method}

All organic reagents and solvents were purchased from Sigma-Aldrich and used without further purification. Prior to the deposition of $\mathrm{ZnO}$ films the solutions to be used were prepared. $0.5 \mathrm{M}$ of $\mathrm{Zinc}$ sulphate $\left(\mathrm{ZnSO}_{4} \cdot 7 \mathrm{H}_{2} \mathrm{O}\right)$ solution was prepared by dissolving $0.434 \mathrm{~g}$ of $\mathrm{ZnSO}_{4} .7 \mathrm{H}_{2} \mathrm{O}$ salt in 100 mls of double distilled water and this solution served as $\mathrm{Zn}^{2+}$ ion precursor. $0.5 \mathrm{M}$ of Citirc acid was prepared by dissolving $0.22 \mathrm{~g}$ of citric acid in $100 \mathrm{mls}$ of double distilled water. This solution served as precursor for oxygen. $24.50 \%$ $\mathrm{NH}_{4} \mathrm{OH}$ solution served as both complexing agent and $\mathrm{pH}$ adjuster. All FTO substrates were cleaned by ultrasonic treatment in acetone for 10 minutes. The cathodic deposition of $\mathrm{ZnO}$ films was performed at 2.07V/SCE potential on the fluorine tin oxide (FTO) conducting glass substrates using the three electrodes setup of electrodeposition. The three electrodes used were the working electrode, reference electrode and the counter electrode. During the deposition, the platinum foil which served as the counter electrode was used as the anode. A saturated calomel electrode (SCE) was used as the reference electrode while the working electrode was the FTO conducting glass substrates which served as the cathode. Dazheng DC-power supply (model: PS-1502A) and two digital multimeters; Mastech (MY-68) and DT9201A $\mathrm{CE})$ were used in the setup for the electrodeposition. In this experiment, three pre-treated fluorine tin oxide (FTO) conducting glass substrates were used. Each of the 3 beakers used for experiment contains various volume of the reagents used for the experiment. The three slides were labeled $\mathrm{ZO}_{1}$, $\mathrm{ZO}_{2}, \mathrm{ZO}_{3}$ respectively. Each of the baths for deposition of $\mathrm{ZnO}$ contains $10 \mathrm{mls}$ of $\mathrm{ZnSO}_{4} \cdot 7 \mathrm{H}_{2} \mathrm{O}, 10 \mathrm{mls}$ of Citric acid and $5 \mathrm{mls}$ of ammonium hydroxide. Zinc sulphate heptahydrate was firstly measured using a $10 \mathrm{mls}$ syringe, transfer to $50 \mathrm{mls}$ beaker, then $10 \mathrm{mls}$ of Citric acid. Lastly, 5 mls of ammonium hydroxide was also measured and transferred to the $50 \mathrm{mls}$ beaker, the mixture was stirred for 5 minute to obtain a homogeneous mixture. The $\mathrm{ZnO}$ films were electrodeposited for different time intervals starting with 30 seconds, 60 secoinds and 90 seconds. Table 1 shows the constituents of each deposition bath. The deposited films were annealled at $573 \mathrm{~K}$. Some properties of $\mathrm{ZnO}$ thin films such as optical and crystal structural properties of the films were determine using spectrophotometer and $\mathrm{x}$ - ray diffractometer.

Table 1. Chemical Constituents for Time Optimization of ZnO Thin Films.

\begin{tabular}{|c|c|c|c|c|c|c|}
\hline Bath Name & Chemicals & Concentration (mol) & Volume (ml) & $\mathbf{p H}$ & Deposition Time (sec.) & Bath Temp. (K) \\
\hline \multirow{3}{*}{1} & $\mathrm{ZnSO}_{4} .7 \mathrm{H}_{2} \mathrm{O}$ & 0.5 & 10.00 & 9.8 & 30 & 303 \\
\hline & Citric acid & 0.5 & 10.00 & & & \\
\hline & $\mathrm{NH}_{4} \mathrm{OH}$ & & 5.00 & & & \\
\hline \multirow{3}{*}{2} & $\mathrm{ZnSO}_{4} .7 \mathrm{H}_{2} \mathrm{O}$ & 0.5 & 10.00 & 9.8 & 60 & 303 \\
\hline & Citric acid & 0.5 & 10.00 & & & \\
\hline & $\mathrm{NH}_{4} \mathrm{OH}$ & & 5.00 & & & \\
\hline \multirow{3}{*}{3} & $\mathrm{ZnSO}_{4} .7 \mathrm{H}_{2} \mathrm{O}$ & 0.5 & 10.00 & 9.8 & 90 & 303 \\
\hline & Citric acid & 0.5 & 10.00 & & & \\
\hline & $\mathrm{NH}_{4} \mathrm{OH}$ & & 5.00 & & & \\
\hline
\end{tabular}

\section{Result and Discussion}

The electrodeposited films are subjected to optical and structural characterization to determine their optical and structural properties. The optical properties of the film were determined using a Janway 6405 UV-visible spectrophotometer while the structure properties of the films were done using Rigaku Ultima IV X-ray diffractometer.

\subsection{Optical Properties}

Optical properties of the deposited films are discussed in this section. The optical properties studies include; optical thickness, absorbance, transmittance, reflectance, refractive index extinction coefficient, band gap energy and optical conductivity. Figure 1 reveals the plot of thickness against time of deposition. This result revealed that thickness of the films increases linearly as time of deposition increases. Optimal thickness of $0.27 \mu \mathrm{m}(270 \mathrm{~nm})$ was obtained for film deposited at 90 seconds. Figure 2 shows the plot of absorbance against wavelength. Absorbance of the films is moderate within UV region with numerical values between 0.42 at $320 \mathrm{~nm}$ to 0.28 at $400 \mathrm{~nm}$. These values decrease slowly within VIS - NIR region with a minimal absorbance value of 0.01 at $1100 \mathrm{~nm}$ for film deposited at 30 seconds. The absorbance can be seen to increase as time of deposition increases. 


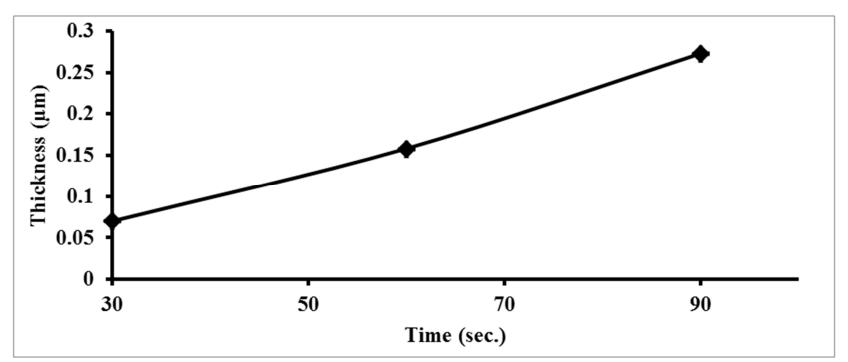

Figure 1. Plot of Thickness ( $\mu \mathrm{m})$ against Time of Deposition (sec).

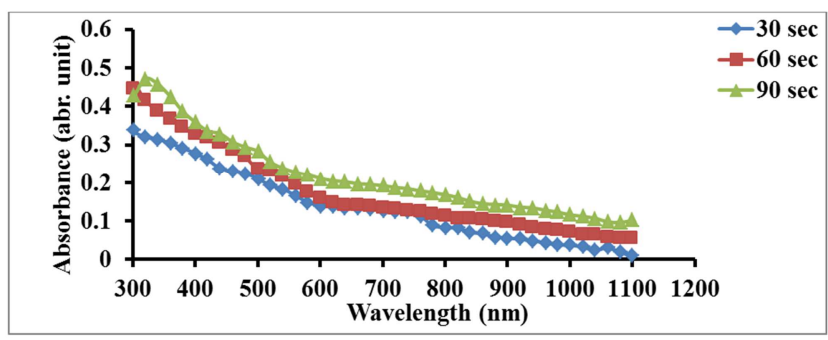

Figure 2. Plot of Absorbance (abr. unit) against Wavelength (nm).

Figure 3 shows a plot of percentage against wavelength. Transmittance values of the film within the UV region range from $33.73 \%$ to $46.13 \%$. In VIS - NIR region, the transmittance ranges from $46.88 \%$ to $97.72 \%$. This shows that the electrodeposited films of $\mathrm{ZnO}$ transmit more of VIS - NIR radiation more than UV. The transmittance decreases as time of deposition increases. Figure 4 shows the graph of reflectance of the films plotted against wavelength. In general, the films are of low reflectance ranging from 0.2 to 0.01 . The reflectance decreases as wavelength increases but decreases as time of deposition increases. Figure 5 is the graph of refractive index of the deposited $\mathrm{ZnO}$ films plotted against wavelength. Refractive index of the films decreases as wavelength increases but increases as time of deposition increases. An optimal refractive index of 2.62 and minimal value of 1.26 were obtained for the deposited films. Figure 6 is the graph of extinction coefficient of the films plotted against wavelength. Extinction coefficient of the films decreases as wavelength increases. The values also increase as time of deposition increases. Peak value of $3.76 \times 10^{-2}$ was obtained at $320 \mathrm{~nm}$ for films deposited at 90 seconds while the least value of $1.59 \times 10^{-3}$ was obtained for film deposited at 30 seconds. These values confirmed that the absorption rate of radiation by the films is higher in UV region than in VIS - NIR regions. Figure 7 is the graph of optical conductivity of the films plotted against wavelength. Optical conductivity of the films decreases exponentially as wavelength increases. Also, optical conductivity increases slightly as time of deposition increases. Peak value of $91.86 \times 10^{12} s^{-1}$ was obtained at $300 \mathrm{~nm}$ for film deposited at 60 seconds while the minimal value of $2.33 \times 10^{10} s^{-1}$ was obtained at $1100 \mathrm{~nm}$ for films deposited at 30 seconds. This result shows that films of $\mathrm{ZnO}$ conduct optically in UV region more than in VIS - NIR regions of the electromagnetic spectrum. The optical results obtained are in agreement with the results of $[11,18]$.

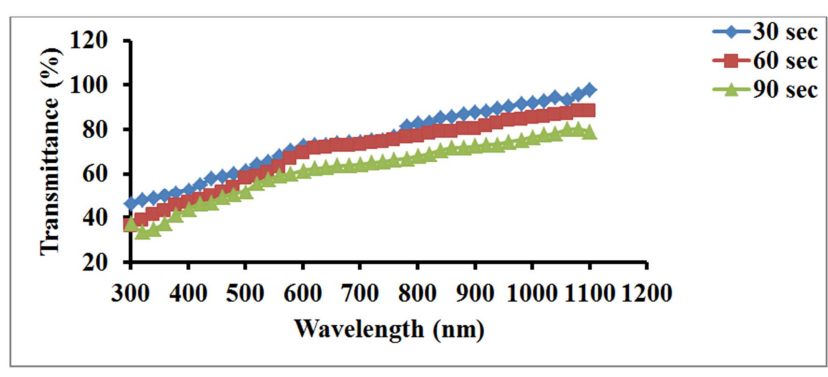

Figure 3. Plot of Percentage Transmittance against Wavelength (nm).

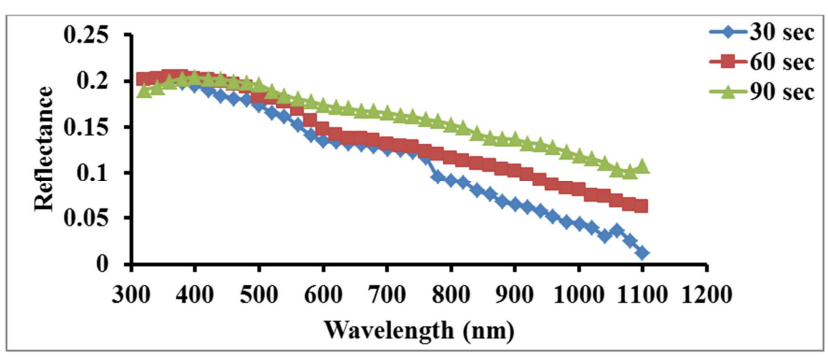

Figure 4. Plot of Reflectance against Wavelength (nm).

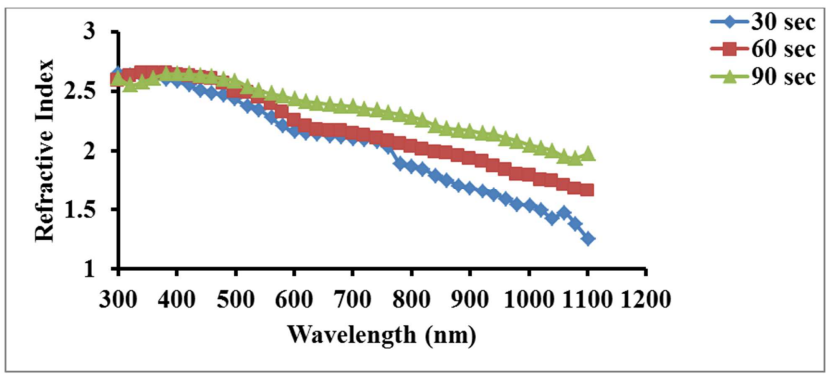

Figure 5. Plot of Refractive Index against Wavelength (nm).

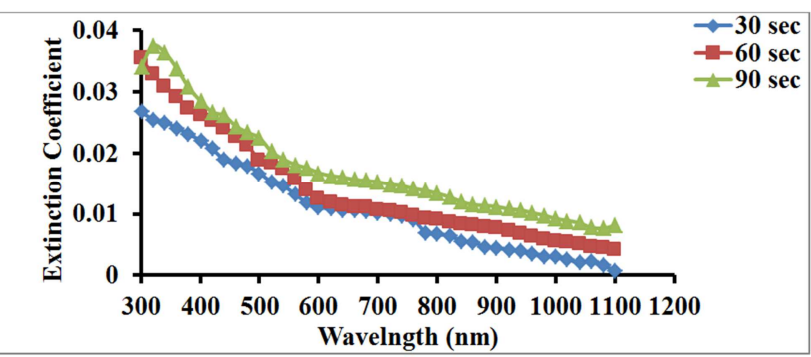

Figure 6. Plot of Extinction Coefficient against Wavelength (nm).

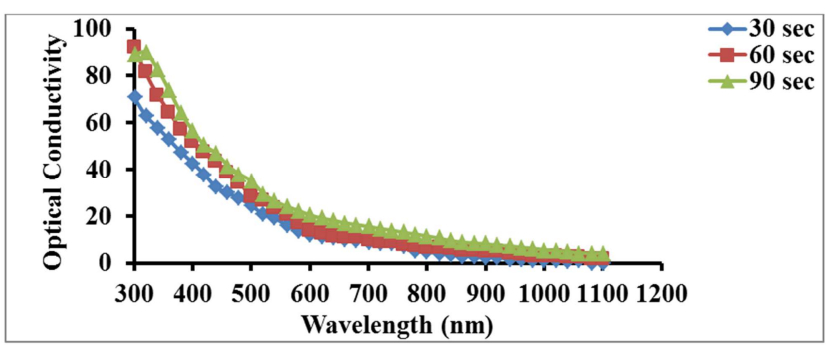

Figure 7. Plot of Optical Conductivity against Wavelength (nm).

Figure 8 shows the graph of the plot of $(\alpha h v)^{2}$ against photon energy to determine the band gap of the films. Band gap was determined by extrapolating the straight portion to the photon energy axis at $(\alpha h v)^{2}=0$, the band gap was 
found to be between $3.30 \mathrm{eV}$ and $3.60 \mathrm{eV}$. This band gap values are in line with works reviewed by $[7,18,19]$.

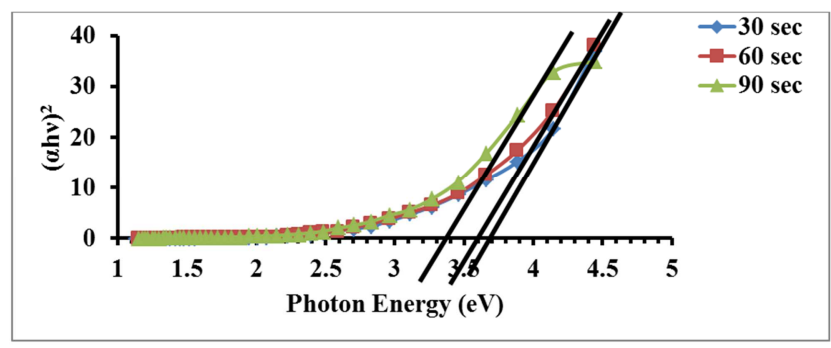

Figure 8. Plot of $(\alpha h v)^{2}$ against Photon Energy.

\subsection{Structural Analysis}

Figure 9 shows the crystal structural studies of the $\mathrm{ZnO}$ nanofilm deposited at 30 seconds. The result shows (100), (002), (101), (102), (110) distinct diffraction peaks with preferred orientation in (002) plane. The film exhibits good crystallinity and all the peaks are indexed for a hexagonal phase of wurtzite $\mathrm{ZnO}$ with lattice constants of $a=b=$ $3.249 \AA$, and $c=5.206 \AA$, which are in good agreement with the reported standard values (JCPDS No. 36-1451). The average crystallite size of $43.04 \mathrm{~nm}$ was deduced by the inverse proportional relation of the full width at half maximum (FWHM), as predicted by Debye-Scherrer's formula.

$$
D=\frac{0.9 \lambda}{\beta \cos \theta} \text {. }
$$

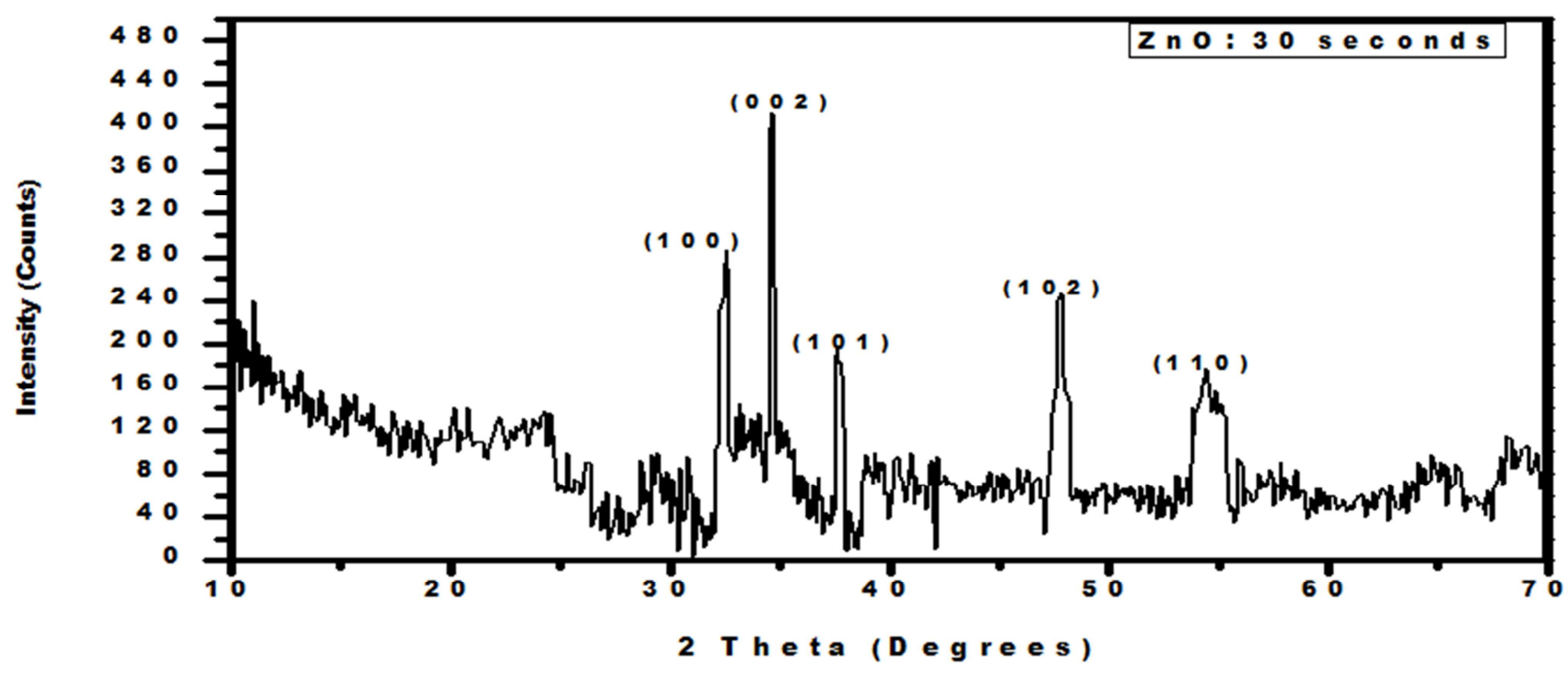

Figure 9. X-Ray Diffraction Pattern of ZnO Films Deposited at 30 seconds.

Where $\mathrm{D}$ is the crystalline size, $\lambda$ is the $\mathrm{X}$-ray wavelength used (1.5406 $\AA$ ), $\beta$ is the full width at half maximum (FWHM) intensity, and $\theta$ is the Bragg's angle which is the diffracting angle. The crystallite size of $43.04 \mathrm{~nm}$ confirmed that the deposited films of $\mathrm{ZnO}$ are in nanoscale. Table 1 shows the values of 2 theta angles, $\mathrm{d}$ - spacing and miller indices (hkl) for the deposited $\mathrm{ZnO}$ nanofilms.

Table 2. XRD results of Film Deposited at 30 Seconds.

\begin{tabular}{lll}
\hline 2 Theta (Degrees) & d - spacing $(\AA)$ & [hkl] \\
\hline 32.57 & 2.747 & {$[100]$} \\
34.66 & 2.605 & {$[002]$} \\
37.63 & 2.388 & {$[101]$} \\
47.81 & 1.901 & {$[102]$} \\
54.39 & 1.685 & {$[110]$} \\
\hline
\end{tabular}

\section{Conclusion}

We have successfully electrodeposited nanofilms of $\mathrm{ZnO}$ using Zinc sulphate as precursor for zinc ion, citirc acid and
$24.50 \% \mathrm{NH}_{4} \mathrm{OH}$ solution as complexing agent. The band gap of the film is between 3.30 to $3.60 \mathrm{eV}$. The films show high absorbance of about 0.47 abr. unit in UV region and high transmittance of $97.72 \%$ in the NIR regions of electromagnetic spectrum shows that $\mathrm{ZnO}$ is a transparent semiconducting film. Reflectance of the film is very low in all the wavelength region. Optimal optical thickness of $270 \mathrm{~nm}$. Optical is found to increase as time of deposition increases. Index reflection for the films range from $1.26-$ 2.62. These optical results of deposited zinc oxide vary as the time of deposition increases. These optical properties suggest that the deposited film can be applied in thin film transistors which required a wide band gap material at room temperature and transparent in the visible region of the spectra. They are also suitable for solar cell applications. $\mathrm{X}$ - ray diffraction analysis of the film deposited at 30 seconds confirmed that the deposited film is zinc oxide. The crystallite size of the deposited film is $43.04 \mathrm{~nm}$ which suggest that the films are nano-crystalline in nature. 


\section{References}

[1] Anderson J. and Chris G. V., (2009), Fundamentals of zinc oxide as a semiconductor, Rep. Prog. Phys. 72, 126501, 2.

[2] Romero R., López M. C., Leinen D., Martin F. and RamosBarrado J. R., (2004), Electrical properties of the n-ZnO/c-Si heterojunction prepared by chemical spray pyrolysis, Materials Science and Engineering B 110, 87-93.

[3] Karakaya S. and Özbaş Ö. (2013), Deposition and Characterization of Zinc Oxide Films, Journal of Natural and Applied Science 17 (3), Pp. 49-51.

[4] Özgür, Ü. Alivov, Ya. I.; Liu, C.; Teke, A.; Reshchikov, M. A.; Doğan, S.; Avrutin, V.; Cho, S.-J.; Morkoç, H. (2005). 'A comprehensive review of $\mathrm{ZnO}$ materials and devices." Journal of Applied Physics. 98 (4): 041301.

[5] Oliveira F. F., Proenca M. P., Araújo J. P. and Ventura J. (2016). Electrodeposition of $\mathrm{ZnO}$ thin films on conducting flexible substrates. Journal of Materials Science, Volume 51, Issue 12, pp 5589-5597.

[6] Hassiba Rahal, Rafiaa Kihal, Abed Mohamed Affoune, Mokhtar Ghers and Faycal Djazi (2017). Electrodeposition and characterization of $\mathrm{ZnO}$ thin films using sodium thiosulfate as an additive for photovoltaic solar cells. Journal of Semiconductors, Volume 38, Number 5, 053002.

[7] Bolarinwa H. S., Onuu M. U., Fasasi A. Y., Alayande S. O., Animasahun L. O. Abdulsalami I. O., Fadodun O. G. and Egunjobi I. A. (2017), Determination of optical parameters of zinc oxide nanofibre deposited by electrospinning technique, Journal of Taibah University for Science.

[8] Franklin J. B., Zou B., Petrov P., McComb D. W., Ryan M. P. and McLachlan M. A. (2011), Optimised pulsed laser deposition of $\mathrm{ZnO}$ thin films on transparent conducting substrates, Journal of Materials Chemistry, Issue 21, pp. 81788182.

[9] Ghafouri, V., Shariati M. and Ebrahimzad A., (2012), Photoluminescence investigation of crystalline undoped $\mathrm{ZnO}$ nanostructures constructed by RF sputtering, Scientia Iranica, Volume 19, Issue 3, Pages 934-942.

[10] Wallace I., Eshu O. V., Chukwunonso O. B., Okoro U. C.,
(2015) Synthesis and Characterization of Zinc Oxide $(\mathrm{ZnO})$ Nanowire. Journal of Nanomedicine and Nanotechnology, Volume 6, Issue 5, 1000321 .

[11] Ezenwa I. A. (2012), Synthesis and Optical Characterization of Zinc Oxide Thin Film, Research Journal of Chemical Sciences Vol. 2(3), pp. 26-30.

[12] Giri P. K., Patel P. K., Panchal C. J, Bhattacharyya S., Kumari S., Singh D. K., Kheraj V. A., Shah N. M., Vakil P. D., Patel K. J., Desai M. S., Desai R. R., Lakshminarayana D. and Patel P. B. (2007), Studies on Zinc Oxide Nanorods Grown by Electron Beam Evaporation Technique. Synthesis and Reactivity in Inorganic, Metal-Organic, and Nano-Metal Chemistry, 37:437-441.

[13] Qiu, D. J., Wu, H. Z., Feng, A. M., Lao, Y. F., Chen N. B. and $\mathrm{Xu}$ T. N. (2004). Annealing effects on the microstructure and photoluminescence properties of Ni-doped $\mathrm{ZnO}$ films. Applied Surface Science 222 263-268.

[14] Rosmalini Ab Kadir, Nurmalina Mohd Taib, Wan Rosmaria Wan Ahmad, Anees Abdul Aziz, Ahmad Sabirin Zoolfakar. (2018). Effect of substrates on Zinc Oxide thin films fabrication using sol-gel method. IOP Conference Series: Materials Science and Engineering 340, 012002 doi:10. 1088/1757-899X/340/1/012002.

[15] Rozati, S. M., Zarenejad F. and Memarian N. (2011). Study on physical properties of indium-doped zinc oxide deposited by spray pyrolysis technique. Thin Solid Films, 520 1259-1262.

[16] Maciąg A., Sagan P., Kuźma M., and Popovych V. (2017). Zinc oxide films prepared by spray pyrolysis. EPJ Web of Conferences 133, 03004. DOI: 10. 1051/ epjconf/713303004.

[17] Qingtao Wang, Guanzhong Wang, Jiansheng Jie, Xinhai Han, Bo Xu and J. G. Hou, (2005). Annealing effect on optical properties of $\mathrm{ZnO}$ films fabricated by cathodic electrodeposition," Thin Solid Films, Vol. 492, pp. 61-65.

[18] Taunk P. B., Das R., Bisen D. P., Tamrakar R. K., Rathor N. (2015), Synthesis and Optical Properties of Chemical Bath deposited $\mathrm{ZnO}$ Thin Film. Karbala International Journal of Modern Science, Vol. 1, pp. $159-165$.

[19] Kumar M. and Sasikumar C. (2014), Electrodeposition of Nanostructured ZnO Thin Film: A Review, American Journal of Materials Science and Engineering, 2014, Vol. 2, No. 2, 1823. 